\title{
An institutional intervention to modify opioid prescribing practices after lumbar spine surgery
}

\author{
Francis Lovecchio, MD, ${ }^{1}$ Jeffrey G. Stepan, MD, MSc, ${ }^{1}$ Ajay Premkumar, MD, MPH, ${ }^{1}$ \\ Michael E. Steinhaus, MD, ${ }^{1}$ Maria Sava, BA, ${ }^{1}$ Peter Derman, MD, MBA, ${ }^{2}$ Han Jo Kim, MD, ${ }^{1}$ and \\ Todd Albert, MD'
}

${ }^{1}$ Hospital for Special Surgery, New York, New York; and ${ }^{2}$ Midwest Orthopaedics at Rush, Chicago, Illinois

\begin{abstract}
OBJECTIVE Patients with lumbar spine pathology are at high risk for opioid misuse. Standardizing prescribing practices through an institutional intervention may reduce the overprescribing of opiates, leading to a decrease in the risk for opioid misuse and the number of pills available for diversion. Without quantitative data on the "minimum necessary quantity" of opioids appropriate for postdischarge prescriptions, the optimal method for changing existing prescribing practices is unknown. The purpose of this study was to determine whether mandatory provider education and prescribing guidelines could modify prescriber behavior and lead to a decreased amount of opioids prescribed at hospital discharge following lumbar spine surgery.
\end{abstract}

METHODS Qualified staff were required to attend a mandatory educational conference, and a consensus method among the spine service was used to publish qualitative prescribing guidelines. Prescription data for 2479 patients who had undergone lumbar spine surgery were captured and compared based on the timing of surgery. The preintervention group consisted of 1177 patients who had undergone spine surgery in the period before prescriber education and guidelines (March 1, 2016-November 1, 2016). The postintervention group consisted of 1302 patients who had undergone spine surgery after the dissemination of the guidelines (February 1, 2017-October 1, 2017). Surgeries were classified as decompression or fusion procedures. Patients who had undergone surgeries for infection and patients on long-acting opioids were excluded.

RESULTS For all lumbar spine surgeries (decompression and fusion), the mean amount of opioids prescribed at discharge was lower after the educational program and distribution of prescribing guidelines $(629 \pm 294$ oral morphine equivalent [OME] preintervention vs $490 \pm 245$ OME postintervention, $p<0.001$ ). The mean number of prescribed pills also decreased ( $81 \pm 26$ vs $66 \pm 22, p<0.001$ ). Prescriptions for 81 or more tablets dropped from $65.5 \%$ to $25.5 \%$. Tramadol was prescribed more frequently after prescriber education $(9.9 \%$ vs $18.6 \%, p<0.001)$. Refill rates within 6 weeks were higher after the institutional intervention $(7.6 \%$ vs $12.4 \%, p<0.07)$.

CONCLUSIONS Qualitative guidelines and prescriber education are effective in reducing the amount of opioids prescribed at discharge and encouraging the use of weaker opioids. Coupling provider education with prescribing guidelines is likely synergistic in achieving larger reductions. The sustainability of these changes is yet to be determined.

https://thejns.org/doi/abs/10.3171/2018.8.SPINE18386

KEYWORDS opioid prescriptions; lumbar spine surgery; prescribing guidelines

$\mathrm{S}$ PINE surgeons are on the front lines of the current opioid epidemic, treating patients at particularly high risk for opioid use disorders. In an evaluation of pain intensity after 179 surgical procedures across multiple specialties, patients who had undergone spine surgery reported the highest pain scores. ${ }^{11}$ In those who use pre- scription opioids long term, spinal conditions are the most common diagnoses for the first prescription, ${ }^{29}$ and more than half of the patients who use opioids have chronic back pain. ${ }^{6}$

Unfortunately, there is a paucity of data on the quantity of opioids to prescribe after spine surgery, leaving provid-

ABBREVIATIONS EMR = electronic medical record; OME = oral morphine equivalent.

SUBMITTED March 29, 2018. ACCEPTED August 24, 2018.

INCLUDE WHEN CITING Published online February 5, 2019; DOI: 10.3171/2018.8.SPINE18386. 
ers trapped between the need to alleviate suffering and a lack of evidence on what constitutes an "appropriate minimum quantity" for a postdischarge prescription. ${ }^{10,21}$ This conflict has contributed to overprescribing, often leaving patients with leftover narcotic pills after surgery. ${ }^{12,19,28}$ The push to reduce opioid prescriptions is further supported by the lack of an association between increased opioid dosage and pain relief, $, 13,25$ multiple side effects (including death), ${ }^{4}$ an association with postoperative complications, ${ }^{4,8}$ and the legal ramifications of careless prescribing.?

The American Academy of Orthopaedic Surgeons has called for the standardization of opioid prescribing practices in an attempt to decrease overprescribing and the number of pills available for diversion. ${ }^{1}$ Institutional interventions have been shown to reduce the quantity and variance in opioid prescriptions after hand and general surgery. ${ }^{14,15,30}$ Prescriber education on the risks of opioid use and a written guideline on institutional practices form the two common tenets of such interventions. Currently, the lack of knowledge regarding average postoperative opioid consumption following lumbar spine surgery inhibits the ability to form quantitative evidence-based guidelines. Arbitrarily assigning a number of pills to each surgery without high-quality data on opioid consumption patterns could run the risk of widespread uncontrolled pain or an abundance of unused pills. Thus, qualitative guidelines may prove effective in reducing the number of opioids prescribed at discharge. The purpose of the present study was to investigate the impact of a provider education program and qualitative guidelines on opioid prescriber behaviors after lumbar spine surgery. We hypothesized that our institutional intervention would lead prescribers to decrease the amount of opioids given after lumbar spine surgery.

\section{Methods \\ Overview}

At an orthopedic specialty hospital, all employees eligible to prescribe opioid medications were required to attend a mandatory educational program in November 2016. Over the next 4 months, qualitative prescribing guidelines were conceived by the spine surgery service and were disseminated in February 2017. After institutional review board approval, prescribing data from the hospital's electronic medical record (EMR) were reviewed to compare the number, type, and amount of opioid prescriptions in the 8-month periods before and after the institutional intervention.

\section{Prescriber Education}

At our institution, an opioid task force was created that consisted of orthopedic surgeons, anesthesiologists, pain specialists, hospital administrators, legal counsel, and house staff representatives. The task force created a 1-hour educational lecture addressing the scope and origin of the opioid epidemic, the role of orthopedic prescribers, multimodal analgesia, the statewide controlled substance registry, and the state laws mandating electronic prescribing of opioids. All prescribers completed the program in either a live lecture or web series format.

\section{Development of Prescribing Guidelines}

Each orthopedic subspecialty service was tasked with the creation of its own prescribing guidelines, which were reviewed by the opioid task force. An initial literature review revealed a dearth of studies directly measuring the amount of postdischarge opioids consumed after spine surgery. ${ }^{21}$ Therefore, a consensus-based method was utilized to establish guidelines. This method consists of gathering experts in a particular field and allowing them to convene in a structured environment, using their combined clinical experiences and expertise along with the best available evidence to formulate a solution to a challenging clinical issue. ${ }^{9}$ A consensus-based methodology has been utilized by a variety of fields and institutions, including the National Institutes of Health and the Centers for Disease Control and Prevention, to advance practice when evidence is lacking. ${ }^{16,17}$ Furthermore, consensus methods have been utilized in establishing the foundation for successful opioid prescriber interventions in hand and general surgery. ${ }^{15,30}$

A multidisciplinary committee of pain medicine physicians, anesthesiologists, nurse managers, and spine surgeons was charged with developing a set of guidelines for opioid prescribing after spine surgery (Fig. 1). A literature review was performed for the committee to cross-reference with their clinical experience. Given the lack of evidence on the quantity of opioids consumed upon hospital discharge after spine surgery, ${ }^{21}$ the committee decided on a qualitative approach to the prescribing guidelines, relying on a patient's inpatient or postanesthesia care unit (PACU) opioid consumption to inform the outpatient prescription. At our institution, the most common opioids prescribed at discharge included tramadol, oxycodone/acetaminophen, hydrocodone/acetaminophen, and hydromorphone. The committee believed that oxycodone/acetaminophen 5-325 mg, hydrocodone/acetaminophen 5-325 mg, tramadol $50 \mathrm{mg}$, and hydromorphone $2 \mathrm{mg}$ provided clinically comparable relief and were appropriate for postoperative discharge prescriptions. In cases in which a combined pill would lead to the ingestion of dangerous amounts of acetaminophen, the two components were broken up into separate prescriptions. The opioid prescription was emphasized as only one part of a multimodal approach to postoperative pain control. ${ }^{20}$ Certain factors were believed to be especially pertinent to patients undergoing spine surgery, such as minimizing the concomitant use of benzodiazepines and muscle relaxants, avoiding long-acting opioids, and using only one type of opioid. Lastly, given the high prevalence of opioid use in patients with lumbar spine pathology, ${ }^{6,32}$ the guidelines make special note that they are to apply to opioid-naïve patients only. Guidelines were disseminated for use on the hospital website, in patient care areas, and in the resident and physician assistant workrooms starting in February 2017.

\section{Determining the Impact of Education and Guidelines}

All opioid medications prescribed at discharge were extracted from the hospital-wide EMR. We included all opioid prescriptions written at discharge following lumbar spine surgery in the 8 months before prescriber education (March 1, 2016-November 1, 2016) and in the 8 months 
POLICY STATEMENT/PURPOSE: Promote judicious prescribing practices; encourage prescribers to employ conservative opioid prescribing practices to enhance patient safety \& minimize risks of overuse \& diversion.

\section{CONTENT APPLIES TO: Post-operative inpatient \& ambulatory patients with no history of opioid dependency (chronic opioid treatment with daily use $>6$ months).}

\section{PRINCIPLES OF PRESCRIBING OPIOIDS AT DISCHARGE:}

1. Generally, we recommend that you prescribe only one (1) short-acting opioid. In situations where you prescribe two (2) short-acting opioids, the combined number of pills should not exceed the recommended maximum to prescribe (below). Further, please ensure that the patient understands that one opioid is for mild pain and the other for severe to moderate pain.

2. Do not prescribe long-acting opioids.

3. Consider discontinuing or decreasing benzodiazepines (e.g. Valium, Xanax) with concurrent use of opioids. Consult with attending surgeon/medical doctor or pain management specialist if patient will take benzodiazepines and opioids concurrently since higher doses of benzodiazepines are associated with increased respiratory risks.

4. Consult with your attending surgeon.

\section{RECOMMENDED PRESCRIBING PRACTICE:} ALL SPINE PROCEDURES:

- Consider one of the following short-acting opioid options to initiate therapy:

\begin{tabular}{|lccc|}
\hline Medication & Dosage/Route & Frequency & Supply to Determine \\
\hline $\begin{array}{l}\text { - } \\
\text { - } \text { Nercocet } 5 / 325 \mathrm{mg}\end{array}$ & 1-2 PO & Q3-4h & 2 week \\
- Dilaudid $2 \mathrm{mg}$ & & & \\
\hline
\end{tabular}

FIG. 1. Prescribing guidelines of the spine service. $h=$ hour; $P O=$ by mouth; $Q=$ every.

after dissemination of the guidelines (February 1, 2017October 1, 2017). Procedures were categorized as decompression only (decompression of neural elements without placement of hardware) or fusion (placement of instrumentation, including pedicle screws, dynamic stabilization, or interbody devices). Because of the way procedures are coded in our EMR, only the primary procedure could be recorded, and other specifics, such as the use of combined approaches, osteotomies, or number of fusion levels, could not be included. Incision and drainage and hematoma evacuations were excluded from the analysis. Prescriptions written by chronic-pain providers, long-acting opioids, or atypical opioids not addressed by the prescribing guidelines were excluded from the analysis as these represented medications written for patients whose postoperative pain relief regimens were managed by pain specialist teams and thus not covered by the prescribing guidelines. ${ }^{3}$

Opioid prescriptions given prior to mandatory education and the distribution of guidelines belonged to the "preintervention," or control, group (March 1, 2016-November 1,2016), and prescriptions given after the dissemination of guidelines were categorized in the "postintervention" group (February 1, 2017-October 1, 2017). The number of pills and the type of opioids prescribed were recorded for each prescription. To facilitate comparisons of the amount of opioids prescribed, all prescriptions were converted into the oral morphine equivalent (OME) by multiplying the number of pills by the conversion factor. The following conversion factors were used: hydrocodone
$5 \mathrm{mg}=5 \mathrm{OME}$, oxycodone $5 \mathrm{mg}=7.5 \mathrm{OME}$, codeine 30 $\mathrm{mg}=4.5 \mathrm{OME}$, hydromorphone $2 \mathrm{mg}=8 \mathrm{OME}$, tramadol $50 \mathrm{mg}=5$ OME, morphine $1 \mathrm{mg}=1$ OME . To evaluate outpatient refill rates before and after the intervention, New York State Prescription Monitoring Program data were retrieved from the charts of a random sample of 250 patients from each cohort (500 patients total). These data were reviewed to determine refill rates within 6 weeks after surgery.

\section{Statistical Analysis}

Number of pills, OME, body mass index, and age were compared between the two groups by using Mann-Whitney U-tests with Bonferroni corrections of type I error thresholds to adjust for multiple comparisons. Categorical variables (rates of opioid medication classes prescribed and rates of prescriptions in defined pill ranges) before and after guidelines were compared using Pearson's chisquare test. To estimate the decrease in pills prescribed after prescriber education and guidelines dissemination, we first extrapolated the average annual number of each type of procedure performed based on 8 months of post-guidelines data. To calculate the hypothetical "number of pills saved" by the intervention, we used the following formula: pills saved $=$ (average procedures per year post-guidelines) $\times$ (mean pre-education pills - mean post-guidelines pills). All statistical analyses were performed using SPSS version 22 (IBM Corp.). 
TABLE 1. Demographic and procedural characteristics of patient sample

\begin{tabular}{|c|c|c|c|}
\hline Variable & $\begin{array}{l}\text { Preintervention } \\
\text { Group }\end{array}$ & $\begin{array}{l}\text { Postintervention } \\
\text { Group }\end{array}$ & $\begin{array}{c}\mathrm{p} \\
\text { Value }\end{array}$ \\
\hline No. of patients & 1177 & 1302 & \\
\hline Sex & & & 0.133 \\
\hline Male & $673(57.2 \%)$ & $706(54.2 \%)$ & \\
\hline Female & $504(42.8 \%)$ & $596(45.8 \%)$ & \\
\hline Age in yrs & $57 \pm 16$ & $58 \pm 16$ & 0.335 \\
\hline $\mathrm{BMI}\left(\mathrm{kg} / \mathrm{m}^{2}\right)$ & $28.4 \pm 5.7$ & $28.2 \pm 5.6$ & 0.354 \\
\hline ASA classification & & & 0.943 \\
\hline I & $109(9.3 \%)$ & $118(9.1 \%)$ & \\
\hline II & $866(73.6 \%)$ & $970(74.5 \%)$ & \\
\hline III & $178(15.1 \%)$ & $184(14.1 \%)$ & \\
\hline Not recorded & $24(2.0 \%)$ & $30(2.3 \%)$ & \\
\hline Primary procedure & & & 0.337 \\
\hline $\begin{array}{l}\text { Laminectomy/ } \\
\text { decompression }\end{array}$ & $492(41.8 \%)$ & $544(41.8 \%)$ & \\
\hline Microdiscectomy & $266(22.6 \%)$ & $263(20.2 \%)$ & \\
\hline Ant interbody fusion & $75(6.4 \%)$ & $99(7.6 \%)$ & \\
\hline $\begin{array}{l}\text { Direct lat interbody } \\
\text { fusion }\end{array}$ & $99(8.4 \%)$ & $103(7.9 \%)$ & \\
\hline $\begin{array}{l}\text { Pst fusion w/ or w/o } \\
\text { interbody }\end{array}$ & $245(20.8 \%)$ & $293(22.5 \%)$ & \\
\hline
\end{tabular}

Ant $=$ anterior $; \mathrm{ASA}=$ American Society of Anesthesiologists; $\mathrm{pst}=$ posterior Data reported as no. (\%) or mean \pm standard deviation. A type I error of $p<$ 0.05 was considered statistically significant.

\section{Results}

Demographics and procedure types were similar in the pre- and postintervention cohorts (Table 1). For all procedures (decompression and fusion), there was a significant decrease in the OME and number of tablets prescribed in the postintervention cohort (Table 2). This pattern was repeated in the decompression and fusion groups. The decompression group had the largest drop in both the OME and the number of pills prescribed. Furthermore, the standard deviation of the number of pills and OME prescribed also decreased in all groups after guidelines were implemented. The median number of pills similarly decreased for each group. For all procedures, a median of 90 (IQR 65-90) was prescribed in the preintervention cohort and 70 (IQR 56-84) in the postintervention cohort ( $\mathrm{p}<$ 0.001 ). Similarly, after the guidelines, there were decreases in the median number of pills prescribed after decompres-

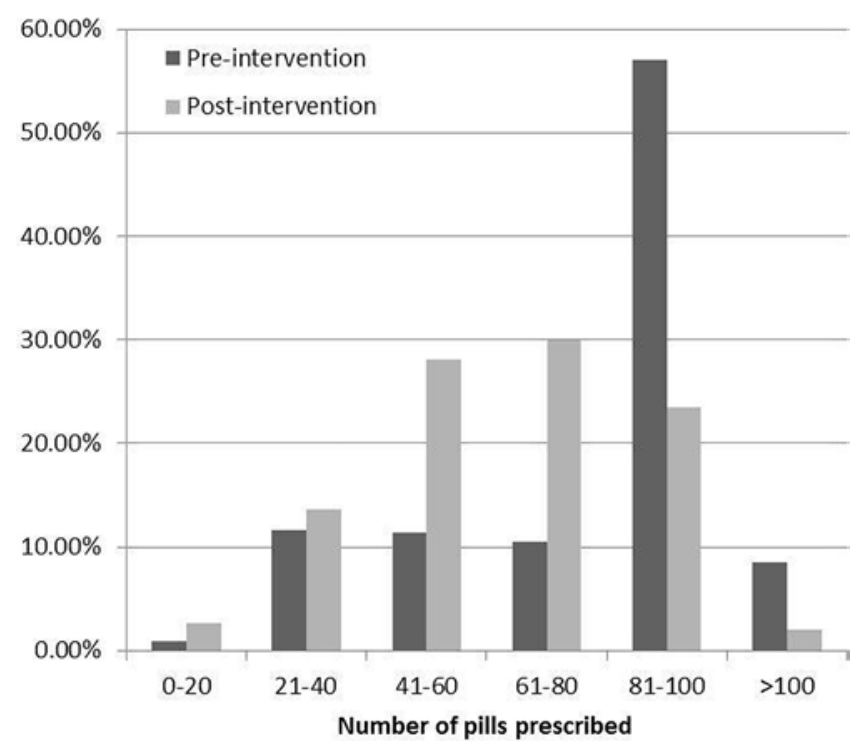

FIG. 2. Rate of opioid prescriptions for $n$ number of pills written before and after intervention, all lumbar spine surgeries (decompression and fusion), $p<0.001$.

sion only (90, IQR 70-90 vs 60, IQR 50-80, p < 0.001) and after fusion procedures (90, IQR 60-100 vs 70, IQR $60-84, \mathrm{p}<0.001)$. These decreases theoretically corresponded with a large number of pills saved. For all procedures, we estimated that 26,040 narcotic pills were saved; for decompression, 19,584 pills; and for fusion, 6480 pills.

Figures 2-4 demonstrate that for all groups there was a significant shift in prescriber behavior toward writing prescriptions for a lower number of pills. In the period before the intervention, $65.5 \%$ of prescriptions were written for 81 or more pills, a rate that dropped to $25.5 \%$ after education and guidelines. Prescriptions for quantities in the 41-60 and 21-40 ranges became much more common. The most notable shifts occurred in the decompression group, while those in the fusion group were more modest.

Table 3 demonstrates that prescribers made only modest changes to the types of opioids prescribed after the interventions. This behavior change was mostly manifested by an increase in the rate of tramadol prescriptions written after the interventions (9.9\% preintervention vs $18.7 \%$ postintervention, $\mathrm{p}<0.001)$. Decompression surgeries showed the greatest changes. For fusion surgeries, there was a decrease in the proportion of prescriptions written for hydromorphone (19.4\% preintervention vs $15.6 \%$ postintervention, $\mathrm{p}=0.146$ ), but this decrease was not significant. Outpatient refill rates did not differ but trended

TABLE 2. Changes in opioid prescriptions after prescriber education and guidelines

\begin{tabular}{|c|c|c|c|c|c|c|c|c|c|}
\hline \multirow[b]{2}{*}{ Variable } & \multicolumn{3}{|c|}{ Total } & \multicolumn{3}{|c|}{ Decompression } & \multicolumn{3}{|c|}{ Fusion } \\
\hline & No. of Patients & OME & Tablets & No. of Patients & OME & Tablets & No. of Patients & OME & Tablets \\
\hline Preintervention group & 1177 & $629 \pm 294$ & $81 \pm 26$ & 755 & $604 \pm 241$ & $81 \pm 23$ & 422 & $673 \pm 367$ & $81 \pm 29$ \\
\hline Postintervention group & 1302 & $490 \pm 245$ & $66 \pm 22$ & 816 & $462 \pm 230$ & $63 \pm 22$ & 486 & $537 \pm 263$ & $71 \pm 21$ \\
\hline$p$ value & & $<0.001$ & $<0.001$ & & $<0.001$ & 0.001 & & $<0.001$ & $<0.001$ \\
\hline
\end{tabular}

Data are reported as the means \pm standard deviation, unless indicated otherwise. A type I error of $p<0.05$ was considered statistically significant. 


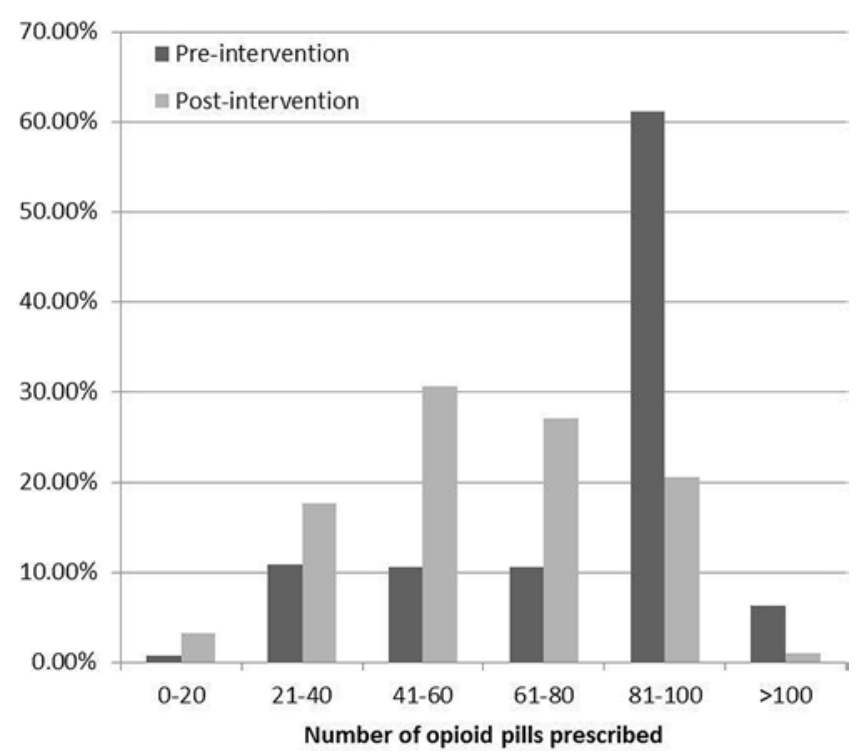

FIG. 3. Rate of opioid prescriptions for $n$ number of pills written before and after intervention, decompression surgeries, $p<0.001$.

toward a higher rate in the postintervention cohort $(7.6 \%$ preintervention vs $12.4 \%$ postintervention, $\mathrm{p}=0.07$ ).

\section{Discussion}

Judicious postoperative opioid prescribing is essential to minimize opioid misuse and limit the number of pills available for diversion. The extent of the opioid epidemic demands that we act now, and until investigations on appropriate postoperative prescription quantities are completed, ${ }^{21}$ the consensus method may serve as a substitute to form institutional guidelines..$^{15,30}$ To our knowledge, this is the first investigation of an institutional intervention on opioid prescription practices after lumbar spine surgery. Our study revealed that qualitative prescribing guidelines combined with an educational program were effective in reducing the amount and variance of postdischarge opioid prescriptions after lumbar spine surgery. In the 8 months after dissemination of the guidelines, the types of opioid medications prescribed remained relatively the same, whereas providers wrote scripts for fewer pills. This change in prescribing practices may have saved the dispensing of over 26,000 narcotic pills.

Our institution saw a smaller decrease in the amount of opioids given after discharge for spinal fusion surgery. This was likely related to the prevalence of adult deformity seen at our hospital. Our spine service performs a large number of adult deformity corrections-of all the fusion surgeries in the study period, at least $32 \%$ were fusions or revision fusions at three or more levels. Given the extent of these procedures, the variability in hospital length of stay, and the inpatient use of opioids, there was likely less of a push to apply a standardized postoperative opioid prescription guideline to these patients, which may have skewed the data toward the null. The procedural complexity in the correction of adult deformity may make it challenging to create standardized quantitative guidelines for postoperative pain management in these patients.

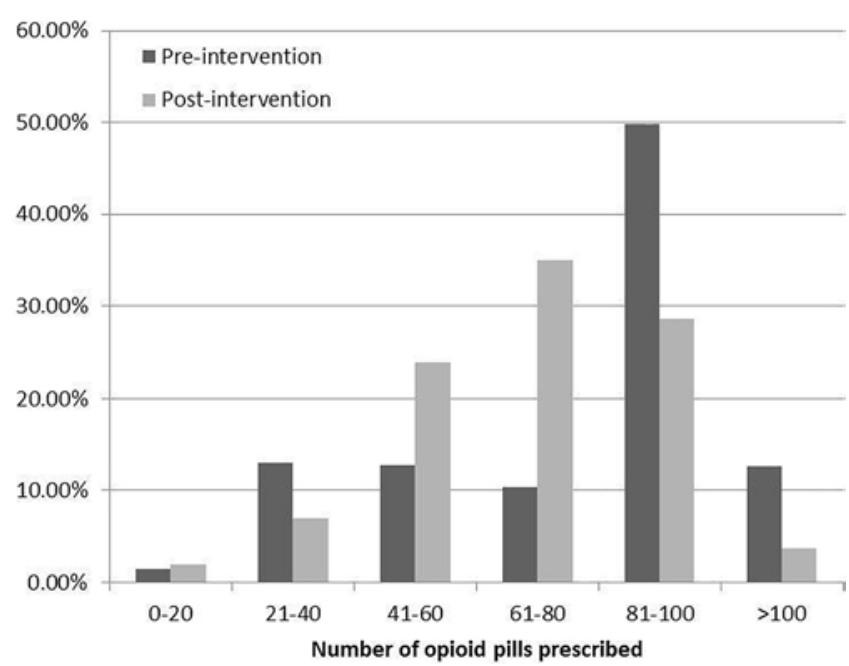

FIG. 4. Rate of opioid prescriptions for $n$ number of pills written before and after intervention, fusion surgeries, $p<0.001$.

While the focus of this study was to evaluate whether the guidelines could affect prescriber behavior, it was interesting to note that on the patient side, refill rates remained relatively unchanged after the guidelines $(7.6 \%$ vs $12.4 \%, \mathrm{p}=0.07)$. We suspect that this difference in refill rates could be significant if applied to a larger population, a finding that would not be unexpected. The overall benefit of decreasing initial opioid prescriptions across the board is not offset by this minor increase in requests for refills, as this difference in refill rates is clinically very small. This finding suggests that overall pain control was not significantly affected by the change in prescription amounts. However, until high-quality data on actual patient opioid consumption is completed, the "minimum necessary quantity" of opioids that minimizes the refill rate and initial prescription OMEs will continue to be elusive.

Successful interventions have been applied to decrease opioid prescriptions after hand and general surgery. ${ }^{15,30}$ For a private practice group of four hand surgeons, Stanek et al. made opioid prescription size recommendations based on the observed distribution of sample data and the consensus among surgeons in the group..$^{30}$ The postoperative pain relief plan was taught to residents, faculty, and nursing staff, while a summary of the postoperative plan was distributed to prescribers in the form of a card. The order set in the EMR was also changed in accordance with this plan. Chart reviews performed 3 months later demonstrated a significant decrease in prescription size in two of four procedural categories, and adherence to the protocol was consistent at 1 year. In a similar intervention, Hill et al. analyzed the opioid consumption of 642 patients who had undergone five common general surgery procedures at an academic hospital, finding that only $28 \%$ of prescribed opioids were used..$^{15}$ Quantitative prescribing guidelines were created based on this information. The group presented these guidelines at grand rounds, general surgery department meetings, in resident forums, and through email. Four months after presentation of the guidelines, significant drops in prescription amounts were identified for all five procedures. 
TABLE 3. Variations in type of opioid prescribed after prescriber education and guidelines

\begin{tabular}{|c|c|c|c|c|c|c|}
\hline \multirow[b]{2}{*}{ Variable } & \multicolumn{2}{|c|}{ Total } & \multicolumn{2}{|c|}{ Decompression } & \multicolumn{2}{|c|}{ Fusion } \\
\hline & Before Intervention & After Intervention & Before Intervention & After Intervention & Before Intervention & After Intervention \\
\hline No. of patients & 1177 & 1302 & 755 & 816 & 422 & 486 \\
\hline \multicolumn{7}{|l|}{ Opioid prescribed ${ }^{*}$} \\
\hline Codeine & $0.3 \%$ & $0.3 \%$ & $0.3 \%$ & $0.2 \%$ & $0.1 \%$ & $0.1 \%$ \\
\hline Tramadol & $9.9 \%$ & $18.7 \%$ & $8.3 \%$ & $18.8 \%$ & $12.6 \%$ & $18.5 \%$ \\
\hline Oxycodone & $69.8 \%$ & $66.2 \%$ & $74.3 \%$ & $69.7 \%$ & $61.6 \%$ & $60.3 \%$ \\
\hline Hydrocodone & $7.8 \%$ & $4.1 \%$ & $9.4 \%$ & $3.8 \%$ & $5.0 \%$ & $4.7 \%$ \\
\hline Hydromorphone & $11.6 \%$ & $10.4 \%$ & $7.3 \%$ & $7.4 \%$ & $19.4 \%$ & $15.6 \%$ \\
\hline Morphine & $0.7 \%$ & $0.3 \%$ & $0.4 \%$ & $0.1 \%$ & $1.2 \%$ & $0.6 \%$ \\
\hline $\mathrm{p}$ value & \multicolumn{2}{|c|}{$<0.001$} & \multicolumn{2}{|c|}{$<0.001$} & \multicolumn{2}{|c|}{0.146} \\
\hline
\end{tabular}

* Includes pills combined with acetaminophen.

Compared to these interventions, ours was similar in that a consensus method was used in the creation of guidelines. However, our department ultimately decided on a qualitative guideline, which differs from the above interventions. While quantitative guidelines are certainly easier for prescribers to follow, without appropriate information (as Hill and colleagues had ${ }^{15}$ ), a quantitative guideline has the propensity to follow the same habits and misconceptions that led to the overprescribing of opioids in the first place. Our institution is actively conducting a prospective study on postoperative opioid use as part of a plan to revise our guidelines and include set quantities based on this information. Quantitative guidelines may lead to larger drops in prescription quantities - the decrease in prescription amounts recorded in our study was not as large as those reported by Hill et al..$^{15}$ (average 53\% drop in prescription quantities) and Stanek et al. ${ }^{30}(15 \%-48 \%$ decreases, depending on procedure). However, an ideal opioid prescribing guideline would likely have both quantitative and qualitative components. Blind adherence to a quantitative guideline may lead to leftover pills for some patients but an underestimation of required pills for others. For example, Hill et al. found that opioid use on the day of discharge was the best indicator of postdischarge opioid use ${ }^{15}$ suggesting that there is a component of individuality that must be taken into consideration.

The interpretation of a qualitative guideline is dependent on the institution's constituents having a shared mental model of the problem at hand. A comprehensive, mandatory educational program can promote a shared mental model. Compared with previous interventions,,${ }^{15,30}$ the prescriber education component of our intervention appears more comprehensive. By giving a thorough overview of the scope and origins of the opioid crisis, along with the legal regulations and electronic registries that ensure safe and responsible prescribing, we believe that we were able to create a shared foundation upon which the institution could address and tackle the problem. Without this form of education, it is possible that the qualitative guidelines would not have been successful in changing prescriber behavior.

Prescriber behaviors also depend on regional and cultural perceptions about opioids and their effectiveness in reducing postoperative pain. While the frequency of oxycodone, hydrocodone, and hydromorphone prescriptions did not drastically change, our institution did have a large rise in the number of postdischarge prescriptions written for tramadol (Table 3). This is consistent with national trends-tramadol has had the second highest rise in prescriptions among all opioids. ${ }^{24}$ There is a common perception that tramadol has low addiction liability, fueled by postmarket research conducted in the 1990s, ${ }^{23}$ combined with translational animal research supporting these claims. ${ }^{26}$ However, this perception of tramadol is oversimplified, as the drug's effects are highly dependent on an individual's CYP2D6 polymorphism..$^{18}$ More recent data reveal tramadol's abuse potential to be much higher than previously thought. ${ }^{2,23}$ Regardless, when choosing a postoperative opioid, tramadol is likely a more responsible choice given its multifaceted mechanism of action in producing pain relief..$^{23}$ Prescriber behavior with regard to opioids also depends on the geographic region. ${ }^{22,27,31} \mathrm{In}$ one investigation of a commercial database, opioids were prescribed at higher rates in the South but at higher doses in the Northeast. ${ }^{27}$ In other countries, opioids are rarely used after surgeries that routinely merit an opioid prescription when performed in the United States. ${ }^{5,13}$ Geographic variation in approaches to postoperative pain relief highlights the need for the standardization of prescribing practices and nationwide prescriber education on the topic. National, comprehensive educational programs coupled with procedure-specific quantitative guidelines would help to mitigate the cultural and geographic variation in prescriber behaviors.

There are several limitations to this study. First, it was limited by an inability to capture patient-level factors such as patient satisfaction with pain relief or actual consumption of opioids. While the goal of this study was to determine whether guidelines and education had any effect on prescriber behavior, the effect of guidelines on patients is complementary information that should form the topic of future investigations and involve a separate methodology. The information we ascertained regarding refill rates indirectly suggests that the guidelines did not greatly affect patients' consumption patterns, but this conclusion cannot be definitively made in light of the study's methodology. 
A second limitation of this study was the length of the postintervention follow-up ( 8 months). While past investigations on prescriber interventions have used follow-up periods of 3-4 months, ${ }^{15,30}$ longer follow-ups are required to determine if these changes are sustained, as has been demonstrated by a previous study. ${ }^{30}$ A third limitation of this study was our inability to capture prescriptions written outside the EMR. While the vast majority of prescriptions given after surgery are written from the hospital, we could not capture prescriptions written by the minority of surgeons' private offices that use EMRs not linked to the hospital EMR. The guidelines specifically prohibited surgeons from sending postoperative opioid prescriptions before the day of surgery, but it was impossible to know how many surgeons followed this recommendation. A fourth limitation relates to data collection from the EMR. When pulling data from the EMR, only the first Current Procedural Terminology code was listed; thus, it is possible that some fusion procedures were mistakenly classified as decompressions. Furthermore, the percent of large fusion cases (i.e., three or more levels) was possibly underestimated. Regardless, the goal of the study was to examine the effect of an institutional intervention on prescriber behavior; thus, this limitation should not affect the overall conclusions of the study.

\section{Conclusions}

Opioid misuse in lumbar spine patients is a challenging problem likely to plague providers well into the future. Further research aimed at identifying and recording opioid use patterns after spine surgery will allow for the creation of better-informed, procedure-specific quantitative prescribing guidelines to supplement existing qualitative guidelines. Until that point, institutions can decrease excessive postoperative opioid prescribing by standardizing prescribing behaviors through education and qualitative recommendations. Comprehensive provider education is essential to create a shared mental model on which the institution can base an intervention. This study demonstrates that qualitative guidelines are effective at reducing the amount and number of opioid pills given after lumbar spine surgery. With this reduction in opioid pills at discharge, requests for refills may expectedly increase, but by a clinically insignificant amount that does not offset the overall reduction in opioid prescriptions. Future research is needed to determine the effect of these changes in prescriber behavior on patient outcomes. Furthermore, as the opioid crisis slows, vigilant tracking of prescribing patterns will be necessary to ensure continued adherence to these trends and to prevent a replaying of history.

\section{References}

1. American Academy of Orthopaedic Surgeons: Opioid Use, Misuse, and Abuse in Orthopaedic Practice. Information Statement 1045. Rosemont, IL: AAOS, 2015 (http://www. aaos.org/uploadedFiles/PreProduction/About/Opinion_ Statements/advistmt/1045 Opioid Use, Misuse, and Abuse in Practice.pdf) [Accessed September 24, 2018]

2. Babalonis S, Lofwall MR, Nuzzo PA, Siegel AJ, Walsh SL: Abuse liability and reinforcing efficacy of oral tramadol in humans. Drug Alcohol Depend 129:116-124, 2013
3. Chou R, Gordon DB, de Leon-Casasola OA, Rosenberg JM, Bickler S, Brennan T, et al: Management of postoperative pain: a clinical practice guideline from the American Pain Society, the American Society of Regional Anesthesia and Pain Medicine, and the American Society of Anesthesiologists' Committee on Regional Anesthesia, Executive Committee, and Administrative Council. J Pain 17:131-157, 2016 (Erratum in J Pain 17:508-510, 2016)

4. Cozowicz C, Olson A, Poeran J, Mörwald EE, Zubizarreta N, Girardi FP, et al: Opioid prescription levels and postoperative outcomes in orthopedic surgery. Pain 158:2422-2430, 2017

5. Devine CA, Yu A, Kasdin RG, Bogart LM, Davis AM, Alcántara Abreu L, et al: Postoperative pain management among Dominican and American health-care providers: a qualitative analysis. J Bone Joint Surg Am 98:e50, 2016

6. Deyo RA, Von Korff M, Duhrkoop D: Opioids for low back pain. BMJ 350:g6380, 2015

7. Drug Enforcement Administration: Cases Against Doctors. Springfield, VA: DEA, 2012 (https://www.deadiversion.usdoj. gov/crim_admin_actions/index.html) [Accessed September 24, 2018]

8. Dunn LK, Durieux ME, Fernández LG, Tsang S, SmithStraesser EE, Jhaveri HF, et al: Influence of catastrophizing, anxiety, and depression on in-hospital opioid consumption, pain, and quality of recovery after adult spine surgery. $\mathbf{J}$ Neurosurg Spine 28:119-126, 2018

9. Fink A, Kosecoff J, Chassin M, Brook RH: Consensus methods: characteristics and guidelines for use. Am J Public Health 74:979-983, 1984

10. Gawande AA: It's time to adopt electronic prescriptions for opioids. Ann Surg 265:693-694, 2017

11. Gerbershagen HJ, Aduckathil S, van Wijck AJM, Peelen LM, Kalkman CJ, Meissner W: Pain intensity on the first day after surgery: a prospective cohort study comparing 179 surgical procedures. Anesthesiology 118:934-944, 2013

12. Gupta A, Kumar K, Roberts MM, Sanders AE, Jones MT, Levine DS, et al: Pain management after outpatient foot and ankle surgery. Foot Ankle Int 39:149-154, 2018

13. Helmerhorst GTT, Lindenhovius ALC, Vrahas M, Ring D, Kloen P: Satisfaction with pain relief after operative treatment of an ankle fracture. Injury 43:1958-1961, 2012

14. Hill MV, Stucke RS, Billmeier SE, Kelly JL, Barth RJ Jr: Guideline for discharge opioid prescriptions after inpatient general surgical procedures. J Am Coll Surg 226:996-1003, 2018

15. Hill MV, Stucke RS, McMahon ML, Beeman JL, Barth RJ Jr: An educational intervention decreases opioid prescribing after general surgical operations. Ann Surg 267:468-472, 2018

16. Hodgkin JE, Balchum OJ, Kass I, Glaser EM, Miller WF, Haas A, et al: Chronic obstructive airway diseases. Current concepts in diagnosis and comprehensive care. JAMA 232:1243-1260, 1975

17. Jenkins KJ, Gauvreau K, Newburger JW, Spray TL, Moller JH, Iezzoni LI: Consensus-based method for risk adjustment for surgery for congenital heart disease. J Thorac Cardiovasc Surg 123:110-118, 2002

18. Kirchheiner J, Keulen JTHA, Bauer S, Roots I, Brockmöller J: Effects of the CYP2D6 gene duplication on the pharmacokinetics and pharmacodynamics of tramadol. J Clin Psychopharmacol 28:78-83, 2008

19. Kumar K, Gulotta LV, Dines JS, Allen AA, Cheng J, Fields $\mathrm{KG}$, et al: Unused opioid pills after outpatient shoulder surgeries given current perioperative prescribing habits. Am J Sports Med 45:636-641, 2017

20. Kurd MF, Kreitz T, Schroeder G, Vaccaro AR: The role of multimodal analgesia in spine surgery. J Am Acad Orthop Surg 25:260-268, 2017

21. Lovecchio F, Derman P, Stepan J, Iyer S, Christ A, Grimaldi 
P, et al: Support for safer opioid prescribing practices: a cata$\log$ of published use after orthopaedic surgery. J Bone Joint Surg Am 99:1945-1955, 2017

22. McDonald DC, Carlson K, Izrael D: Geographic variation in opioid prescribing in the U.S. J Pain 13:988-996, 2012

23. Miotto K, Cho AK, Khalil MA, Blanco K, Sasaki JD, Rawson R: Trends in tramadol: pharmacology, metabolism, and misuse. Anesth Analg 124:44-51, 2017

24. Morley KI, Ferris JA, Winstock AR, Lynskey MT: Polysubstance use and misuse or abuse of prescription opioid analgesics: a multi-level analysis of international data. Pain 158:1138-1144, 2017

25. Nota SP, Spit SA, Voskuyl T, Bot AG, Hageman MG, Ring D: Opioid use, satisfaction, and pain intensity after orthopedic surgery. Psychosomatics 56:479-485, 2015

26. O'Connor EC, Mead AN: Tramadol acts as a weak reinforcer in the rat self-administration model, consistent with its low abuse liability in humans. Pharmacol Biochem Behav 96:279-286, 2010

27. Paulozzi LJ, Mack KA, Hockenberry JM: Variation among states in prescribing of opioid pain relievers and benzodiazepines-United States, 2012. J Safety Res 51:125-129, 2014

28. Rodgers J, Cunningham K, Fitzgerald K, Finnerty E: Opioid consumption following outpatient upper extremity surgery. J Hand Surg Am 37:645-650, 2012

29. Schoenfeld AJ, Jiang W, Chaudhary MA, Scully RE, Koehlmoos T, Haider AH: Sustained prescription opioid use among previously opioid-naive patients insured through TRICARE (2006-2014). JAMA Surg 152:1175-1176, 2017

30. Stanek JJ, Renslow MA, Kalliainen LK: The effect of an educational program on opioid prescription patterns in hand surgery: a quality improvement program. J Hand Surg Am 40:341-346, 2015

31. Thiels CA, Anderson SS, Ubl DS, Hanson KT, Bergquist WJ, Gray RJ, et al: Wide variation and overprescription of opioids after elective surgery. Ann Surg 266:564-573, 2017

32. Zheng P, Kao MC, Karayannis NV, Smuck M: Stagnant physical therapy referral rates alongside rising opioid prescription rates in patients with low back pain in the United States 1997-2010. Spine (Phila Pa 1976) 42:670-674, 2017

\section{Disclosures}

Dr. Albert has been a consultant for NuVasive, Facet Link, Zimmer Biomet, and DePuy Synthes; receives royalties from JP Medical Publishers, Saunders/Mosby-Elsevier, Zimmer Biomet, DePuy Synthes, and Thieme; has served on the Medical Advisory Board for Gentis and United Health Care; has ownership in United Health Care; has direct stock ownership in Gentis, Vital 5, Bonovo Orthopedics Inc., Biomerix, InVivo Therapeutics, Spinicity, Crosstrees Medical, Paradigm Spine LLC, Invuity, ASIP, PMIG, and Pioneer; is an employee of Weill Cornell Medical College; has received support from PCORI, NIH, and ISSG for nonstudy-related clinical or research effort; and is the president of the Scoliosis Research Society and the past president of the Cervical Spine Research Society.

\section{Author Contributions}

Conception and design: Lovecchio, Stepan, Premkumar, Derman. Acquisition of data: Lovecchio, Stepan, Premkumar, Steinhaus, Sava. Analysis and interpretation of data: Lovecchio, Stepan, Premkumar, Sava, Derman. Drafting the article: Lovecchio. Critically revising the article: Lovecchio, Stepan, Premkumar, Derman, Kim, Albert. Reviewed submitted version of manuscript: Lovecchio. Approved the final version of the manuscript on behalf of all authors: Lovecchio. Statistical analysis: Lovecchio, Steinhaus, Sava. Study supervision: Kim, Albert.

\section{Supplemental Information}

Previous Presentations

Portions of this work were presented as proceedings at the Lumbar Spine Research Society Annual Meeting held in Chicago, IL, on April 4-5, 2018.

\section{Correspondence}

Francis Lovecchio: Hospital for Special Surgery, New York, NY. lovecchiof@hss.edu. 